\title{
Desafios da pesquisa em história da arte hoje - pensando história da arte e globalização a partir de experiências com arte, África e Brasil
}

Roberto Conduru

UERJ

London snow Africa, London hole Brazil, obra feita em 1998-1999, por Milton Machado, ${ }^{1}$ é um readymade fotográfico constituído por um par de imagens encontradas e capturadas pelo artista em ruas londrinas: um mapa da África que foi coberto de neve e um buraco no asfalto com forma similar ao mapa do Brasil. Além de questionar as dimensões políticas da cartografia, essa obra pode ser uma boa via de acesso às conexões das artes plásticas à problemática sociocultural afrobrasileira. Seu título, a princípio literal, tem sonoridade que abre significados outros: diferença, identificação, domínio.

Entre outros encaminhamentos, London snow Africa, London hole Brazil aponta a possibilidade e a pertinência de articular artisticamente territórios geopolíticos brasileiros, africanos e outros. Com efeito, África, Brasil e arte são tópicos socioculturais que podem ser conectados entre si e criar um campo de pesquisa heterogêneo e algo impreciso. As relações entre esses tópicos iluminam variados temas, questões, obras, autores, instituições, audiências, sociedades. Constituem um território passível de ser recortado de diversas maneiras, de acordo com diferentes disciplinas, bem como com as intenções e os objetivos que as norteiam.

Para pensar historicamente esse campo múltiplo e não facilmente delimitado é necessário mais do que a inclusão de novos objetos, agentes e instituições, de novos temas e questões na perspectiva tradicional da história da arte. Distante

\footnotetext{
${ }^{1}$ Sobre essa obra e o artista, ver:

www.itaucultural.org.br/aplicesternas/enciclopedia_ic/index.cfm?fuseaction=artistas_biog rafia\&cd_verbete $=2810 \& c d \_i d i o m a=2855$
} 
da noção de estilo, o território circunscrito pela conexão entre África, Brasil e arte pode ser visto como um campo aberto a múltiplos atravessamentos, como uma encruzilhada na qual diferentes elementos, sujeitos, pontos de vistas e modos de pensar se articulam. O que demanda o confronto e a conciliação de teorias, métodos, estruturas discursivas. Portanto, para estudar esse território heteróclito é importante ir além dos limites usuais da história da arte, conectando-a a outras disciplinas e suas tradições.

Nesse sentido, o estudo de relações entre arte, África e Brasil pode ser vinculado à demanda contemporânea pela revisão da abrangência, dos princípios e métodos da história da arte, pode ser associado às tentativas de produção de uma história da arte global. Essa também pode ser vista como uma encruzilhada de diferentes objetos, sistemas de pensamento, agentes, instituições, tradições culturais, modos de ação e reflexão (pesquisar, colecionar, exibir, ensinar, escrever, editar, criar).

Para análise das conexões deflagradas pelo território configurado pela articulação de arte, África e Brasil com relação à história da arte global, esse texto abordará questões a partir de algumas obras de autores que têm contribuído para pensar os desafios, as ideias, as práticas e as realizações neste campo fértil da história da arte na contemporaneidade: David Summers (2003), Thomas da Costa Kaufmann (2004), John Onians (2004; 2006; 2007), Julian Bell (2008 [2007]), James Elkins (2007), David Carrier (2008) e Hans Belting (2009), entre outros.

As obras desses autores indicam que a questão da história da arte global é uma à qual se tem dedicado vários agentes e instituições do campo recentemente. Segundo James Elkins, a história da arte global é a questão mais interessante e importante hoje no campo de história da arte (Apud Kesner, 2007: 81). Embora isso seja discutível, esse sentido de urgência está vinculado ao fato de não serem satisfatórios os modos de incorporação na história da arte das realizações artísticas não Ocidentais e os desdobramentos da arte Ocidental nas supostas margens do sistema artístico mundial. Persiste nos projetos de história da arte global o ideal de abarcar a humanidade por inteiro, que sempre animou as ideias de arte e de história da arte no Ocidente. Contudo, não é apenas a generosidade humana que mobiliza a formulação de uma história da arte que responda ao processo de globalização. Por um lado, a história da arte global responde às cobranças dos discursos pautados pelo multiculturalismo, pela correção política e 
pela lógica pós-colonial, que questionaram o eurocentrismo da história da arte tradicional. No lado oposto, é fomentada pelo interesse das instituições do sistema artístico Ocidental, sobretudo dos grandes museus enciclopédicos, na produção de interpretações históricas da arte que dêem sentidos a seus acervos, na maioria dos casos constituídos em processos arbitrários, incongruentes e pouco humanísticos. Ou, ainda, como observa Aruna D'Souza, a história da arte global está conectada à demanda existente, nos Estados Unidos da América, por cursos universitários com focos internacionais, que está relacionada à necessidade de recrutar estudantes estrangeiros devido à crise do financiamento público da educação, assim como a ênfase na interdisciplinaridade nos anos 1990 estava vinculada aos cortes dos custos operacionais das universidades norteamericanas (D'Souza, 2012, p. 178-179).

Sobressai de imediato a necessidade de ampliar a abrangência espacial do relato histórico, ultrapassar suas fronteiras usuais, pois é preciso alcançar muito além de uma Europa expandida. Ao longo do tempo, em sucessivas configurações em livros publicados por Elie Faure (1990 [1919-1921]), E. H. Gombrich (1972 [1950]), Germain Bazin (1980 [1953]), Arnold Hauser (1990 [1953]), H. W. Janson (1986 [1962]), Fritz Baumgart (1994 [1972]), David Summers (2003), John Onians (2004) e Julian Bell (2008 [2007]), entre muitos outros, a história da arte foi incluindo o Oriente próximo, o Norte da África e algumas regiões da Ásia, a América, sobretudo do Norte, a África e a Oceania. Processo semelhante é observável nos museus, em seus acervos, departamentos e exposições, bem como em cursos acadêmicos, universitários ou não.

Nesse sentido, cabe destacar a proposta de Thomas da Costa Kaufmann para que se articule diferentemente geografia, história e arte. Tendo em vista a virada cultural (cultural turn), o consequente afastamento da ideia de geografia como ciência do espaço físico, e as possibilidades renovadas de diálogo entre história e geografia, ele propõe uma geohistória da arte que articula espaço e tempo na análise dos processos e realizações artísticos (Kaufmann, 2004). Entretanto, o desafio posto pela história da arte frente aos processos contemporâneos de globalização não é apenas fazer uma história da arte que inclua todas as regiões habitadas do globo terrestre, as sociedades humanas em sua totalidade. Colocase o desafio de ultrapassar as configurações nas quais a Europa e os Estados Unidos da América apareçam como centros hegemônicos. Como propõe Piotr 
Piotrowski, é preciso abandonar o que ele denomina como história da arte vertical, cuja hierarquização parte da centralidade européia, por uma história da arte horizontal, que desconstrua a anterior (Piotrowski, 2009). Mas não para configurar outros centros. Com certeza, a distinção entre centro e margens importa para situações e processos específicos na história da arte, exemplos não faltam, como nos processos artísticos relativos à junção de arte, África e Brasil. Mas como a história da arte indica, exaustivamente, centros e margens são circunstanciais, moventes. O que relativiza a noção de centro e margem, fazendo pensar quando e para quem assumem sentidos centralidades e marginalidades. O que implica interpretações da arte baseadas em uma geografia sem centros e margens fixos.

Divisor, ${ }^{2}$ de Ayrson Heráclito, é uma obra que faz sentir o oceano Atlântico como espaço de união de pessoas, sociedades e culturas devido à diáspora africana e ao tráfico negreiro, mas, também, consequentemente, como espaço de separação. Ao compô-la com três grandes caixas de vidro que contêm sal, água e azeite de dendê, Ayrson Heráclito vai além da literalidade daqueles compostos, explorando dimensões metafóricas a partir de sua justaposição. Água e sal estão indissociáveis no mar. Esse azeite é fabricado a partir dos cocos do dendezeiro (Elaeis guineensis), uma árvore com múltiplos sentidos para as religiões afrobrasileiras, nas quais o sumo oleoso de suas sementes pode representar o sangue humano. Soma de matérias que se refere, portanto, ao oceano Atlântico como lugar fulcral dos processos sociais estabelecidos a partir da transposição forçada de africanos para serem escravizados no Brasil, do século XVI ao XIX. Permanecendo estanques, em camadas, em processo de interação parcial e conflituosa, esses materiais remetem à impossibilidade de pensar o Atlântico sem levar em conta os impasses da diáspora e de suas consequências, o mar sem o sangue nele e a partir dele derramado. Assim, simbolizam conexões e disjunções de pessoas, grupos sociais, religiões e culturas entre África e Brasil, práticas e realizações complexas, ainda que também instigantes e, muitas vezes, como nessa obra, belas.

Cisões e articulações, indissociáveis, que ajudam a ver como, na história da arte mais inclusiva e abrangente que se quer produzir, ao rompimento com a

\footnotetext{
2 Sobre essa obra, ver: http://ayrsonheraclitoart.blogspot.com.br/2007/07/divisorvidrosal-gua-e-azeite-de-dend.html
} 
centralidade, a unidade e a estabilidade espacial está vinculada uma estruturação temporal heterogênea e descontínua. Ruptura que pode ser observada na dificuldade de conciliar e acomodar as linhas de tempo cronológicas dos diferentes grupos sociais, como se pode ver, por exemplo, no livro de Julian Bell (2008 [2007]), ou na tentativa de articulação dos processos artísticos que vinculam África e Brasil à história da arte Ocidental. Cisão que também deriva da crítica ao historicismo e de sua temporalidade linear e homogênea. Tanto as obras de Mestre Didi, ${ }^{3}$ cujos artefatos simbólicos elaborados para os cultos de Obaluaê e de Nanã - o xaxará e o ibiri, respectivamente - são testemunhos vivos da permanência de valores, significados, formas e práticas de uma região da África no Brasil, o golfo do Benim, quanto a série de fotos produzidas sobretudo naquela região africana e na Bahia, nas quais Pierre Verger $^{4}$ trouxe à luz sobrevivências, paralelismos e transformações artísticas e culturais nos dois lados do Atlântico falam de estruturas temporais outras que não a sucessão cronológica.

Tanto nas conexões artísticas entre África e Brasil, quanto nas coleções museológicas com elas estruturadas, a variedade de objetos determina uma reflexão histórica que vá muito além do estudo das categorias artísticas tradicionais no Ocidente, bem como de suas distinções entre artes liberais e mecânicas, maiores e menores, plásticas, cênicas e musicais. Objetalidade largamente expandida, obrigando a ultrapassar o objeto, que também se impõe para quem, como Alfred Gell, repensa o conceito de arte ocidental a partir de outras disciplinas e o confronta às práticas culturais de outras sociedades, propondo entender como obras de arte alguns objetos e acontecimentos insólitos tais como armadilhas para capturar animais e plantações de inhame, por exemplo (Gell, 2001; 2005).

Seguindo esse caminho estão as aproximações do conceito europeu de arte a formulações, semelhantes em outros contextos socioculturais. As quais se pautam na observação se as idéias, as práticas e o quadro institucional da arte, tal como existentes no Ocidente, são encontráveis extensivamente no globo terrestre. Ou, ao menos, se é possível estabelecer aproximações com ideias, práticas e instituições similares. Algo semelhante ao trabalho de Rubem

${ }^{3}$ Sobre Mestre Didi, ver: www.mestredidi.org

${ }^{4}$ Sobre Pierre Verger, ver: www.pierreverger.org 
Valentim, ${ }^{5}$ quem, a partir dos símbolos do candomblé e da umbanda em conjunção aos princípios e formas do construtivismo, e da incorporação de outros sistemas simbólicos religiosos (cristianismo, I Ching, Bhagavad Gita e tarô, entre outros) procurou configurar uma nova simbologia de cunho universal.

Tendo em mente que o projeto de Rubem Valentim nunca pretendeu se emancipar do território cultural que ele entendia como sua origem, pode-se perguntar se o desejo de universalidade que anima essas propostas de história da arte global não é uma obsessão. Não seria melhor abandonar a ideia de reunir artefatos produzidos em diferentes contextos socioculturais em museus, livros, disciplinas, currículos sob o conceito de arte? Não seria melhor insistir na particularidade da história da arte Ocidental, ou euro(norte)americana, e constituir outras estruturas analíticas para as demais séries de artefatos? Afinal, não é assim que os museus ainda são constituídos, com setores correspondentes à geopolítica? Mas, assim, a arte Ocidental não deixaria de ser universal, passando a ser um fenômeno humano relativo e, consequentemente, tornando relativo o próprio Ocidente? Ou há sentido em rever a idéia da arte como um universal em outras bases?

Com efeito, recentemente, podem ser indicadas outras propostas de configuração do universal na arte. Em Real Spaces, David Summers propõe que o elemento chave do universalismo artístico é o espaço real constituído pelas pessoas, que o experimentam com seus corpos e o partilham com outros corpos (Summers, 2003). Entendimento claramente social da produção e do uso da arte que está associado às particularidades psicofísicas da corporeidade humana. O que remete a John Onians e sua proposta de história da arte neurológica na qual o universalismo deriva do cérebro humano como elemento de união para além das diferenças socioculturais instauradas ao longo do tempo e no espaço (Onians, 2007). Em clave mais social, David Carrier indica, em $A$ World Art History and its Objects, que uma genuína história da arte mundial começará a ser possível quando historiadores da arte de outros contextos revidarem o olhar que o Ocidente sobre eles aplica e passarem a interpretar a arte Ocidental com princípios a ela estranhos, derivados de suas próprias tradições artísticas (Carrier, 2008).

5 Sobre Rubem Valentim, ver: www.itaucultural.org.br/aplicesternas/enciclopedia_ic/index.cfm?fuseaction=artistas_ver bete $=3245$ 
Aqui, cabe um parêntese. David Carrier foca em quatro grandes tradições: o Ocidente, a China, a Índia e o mundo islâmico, mantendo-se vinculado à ideia de grandes civilizações. Nesse sentido, me faz pensar em contextos e processos menores e impuros. E em como, para os atuantes nas ditas margens do Ocidente, nas antigas sociedades coloniais, pouco sentido faz a diferença estabelecida por Hans Belting entre história da arte mundial e história da arte global, derivada da distinção entre arte mundial (world art), que é caracterizada por oposição à arte européia apresentada como ocidental, e arte global (global art), que é praticada generalizadamente hoje. Desde o início da ação colonial européia no século $\mathrm{XV}$, os intercâmbios estabelecidos entre as diferentes sociedades produziram uma arte impura, ocidentalizada, que a distinção de Hans Belting aceita apenas como um fenômeno recente (Belting, 2009).

É fácil constatar que, frente à questão da globalização, a história da arte está em mudança. Caso se compare os livros de histórias da arte publicadas por Elie Faure, Germain Bazin, Ernst H. Gombrich, e H. W. Janson, Julian Bell, John Onians e David Summers, por exemplo, será possível perceber que a história da arte está se modificando, incorporando de outros modos o que entende como produção artística em todo o mundo. Esse conjunto de obras, editadas entre o início do século XX e o momento atual, indica lentidão nessa mudança, mas também que a disciplina está em fluxo, em processo de transformação.

Reflexões como as de Ulrich Pfisterer (2000) e de Marlite Halbertsma (2008) indicam que a tentativa de formulação de uma história da arte mais abrangente já existiu, particularmente no contexto historiográfico germânico, no final do século XIX e no início do século XX, era variada, complexa e desapareceu. Também The Shape of Time, livro de George Kubler (1962), também pode ser visto como um antecedente do esforço atual para constituição de uma história da arte mundial. O que faz pensar em que medida, como as experiências anteriores, o novo impulso pode se tornar um movimento historiográfico passageiro.

É este um momento de transição ou um fim em si? A meu ver, encarar essa dinâmica recente como uma etapa, como um instante, uma situação de passagem, de transição rumo a uma situação em que a história da arte consiga ser imparcial e equânime com relação aos diferentes tempos e espaços, é ainda desejar correr o risco de totalização. Não sendo factível produzir hoje uma história da arte unificada e totalmente equilibrada, pode-se perguntar se é possível alcançar esse ideal e se o 
mesmo é válido. Assim, essa história da arte global não insistiria na estrutura das metanarrativas, para retomar o pensamento de Jean-François Lyotard (2000 [1979])? Não seria essa história da arte uma continuidade do historicismo? Indo na contra mão, não seria o caso de abandonar o ideal totalizante e a noção de progresso inerente à formulação histórica de matriz hegeliana? Não seria melhor apostar em um mosaico incompleto de histórias parciais, na soma tensa e até mesmo caótica de múltiplas histórias da arte com princípios estruturais, focos espaciais e arranjos temporais particulares, na "pluralidade de narrativas transregionais", como propõe Piotr Piotrowski (2009, p. 84)?

Para fechar esse texto e manter em suspenso a questão, aproximo a história da arte com abrangência global, em seu estágio atual, a Nimbo/Oxalá, de Ronald Duarte. ${ }^{6}$ Nessa instalação performática, o artista articula acontecimento físicoquímico a divindade, remetendo a breve e incontrolável nuvem gerada pela liberação da carga total de equipamentos extintores de incêndio ao orixá da criação para os nagôs. Conexão confirmada por alguns dos atributos de Oxalá: o dia de realização da instauração - sexta-feira -, a cor da fumaça, também predominante nos trajes das pessoas - branco -, o elemento formado temporariamente - nuvem - e uma qualidade do mesmo - onipresença difusa. Nesse trabalho que é também um ex-voto, o artista explora a multiplicidade semântica das religiões e a prática socialmente difundida de difusão subreptícia de seus signos em meio aos códigos culturais brasileiros.

Pode-se pensar o conjunto de ideias e realizações, propostas, métodos e críticas a essa história da arte como uma nuvem que se dissipa. Assim, pode-se prever que um dia ela esteja totalmente espargida, perpassando todos os contextos institucionais historiográficos, artísticos e culturais. Fica a dúvida se, com essa dissipação, manterá alguma unidade e se continuará sendo história da arte, ou terá se tornado outra disciplina. A história da arte global é a extensão da história da arte tradicional, que se aperfeiçoa para se tornar mais abrangente e também mais dominante, ou é uma prática historiográfica crítica que, para ser fiel a antigos e novos ideais, precisa efetivamente se transformar?

\footnotetext{
${ }^{6}$ Sobre essa obra, ver: http://www.ronaldduarte.com/indez.php/nimbo-oxala
} 


\section{Referências}

BAUMGART, Fritz. Breve História da Arte (1972). São Paulo: Martins Fontes, 1994.

BAZIN, Germain. História da Arte (1953). Lisboa: Bertrand, 1980.

BELL, Julian. Uma Nova História da Arte (2007). São Paulo: Martins Fontes, 2008.

BELTING, Hans. Contemporary art as global art. In: BELTING, Hans; BUDDENSIEG, Andrea (Eds.). The Global Art World: Audiences, Markets, and Museums. Ostifildern: Hatje Cantz Verlag, 2009, p. 38-73.

CARRIER, David. A World Art History and its Objects. Pennsylvania: Pennsylvania State University Press, 2008.

D'SOUZA, Aruna. In the wake of 'In the wake of the global turn'. Artmargins, Cambridge, v. 1, n. 23, p. 176-185, 2012.

ELKINS, James (Ed.). Is Art History Global?. New York; London: Routledge, 2007.

FAURE, Élie. História da Arte (1919-1921). São Paulo: Martins Fontes, 1990.

GELL, Alfred. A rede de Vogel: armadilhas como obras de arte e obras de arte como armadilhas. Arte \& Ensaios, Rio de Janeiro, n. 8, p. 174-191, 2001.

GELL, Alfred. A tecnologia do encanto e o encanto da tecnologia. Concinnitas, Rio de Janeiro, v. 1, n. 8, p. 40-63, 2005.

GOMBRICH, Ernst H. História da Arte (1950). São Paulo: Círculo do Livro, 1972.

HALBERTSMA, Marlite. The many beginnings and the one end of worl art history. In: ZIJLMANS, Kitty; VAN DAMME, Wilfried (Eds.). World Art Studies: Exploring Concepts and Approaches.

Amsterdam: Valiz, 2008, p. 91-105.

HAUSER, Arnold. História Social da Arte e da Literatura. (1953). São Paulo: Martins Fontes, 1995.

JANSON, H. W. História da Arte (1962). São Paulo: Martins Fontes, 1986.

KAUFMANN, Thomas DaCosta. Toward a Geography of Art. Chicago: University of Chicago Press, 2004.

KESNER, Ladislav. Is a truly global art history possible? In: ELKINS, James (Ed.). Is Art History Global?. New York; London: Routledge, 2007, p. 81-111.

KUBLER, George. The Shape of Time (1962). New Haven: Yale University Press, 2008.

LYOTARD, Jean-François. A Condição Pós-Moderna (1979). Rio de Janeiro: José Olympio, 2000.

ONIANS, John (Ed.). Art, Culture and Nature: from Art History to World Art Studies. London: The Pindar Press, 2006.

ONIANS, John (Ed.). Atlas of World Art. London: Laurence King Publishing, 2004.

ONIANS, John (Ed.). Neuroarthistory: from Aristotle and Pliny to Baxandall and Zeki. New Haven: Yale University Press, 2007.

PFISTERER, Ulrich. Origins and principles of world art history: 1900 (2000). In: ZIJLMANS, Kitty; VAN DAMME, Wilfried (Eds.). World Art Studies: Exploring Concepts and Approaches. Amsterdam: Valiz, 2008, p. 69-89.

PIOTROWSKI, Piotr. Toward horizontal art history. In: ANDERSON, Jaynie (Ed.). Crossing Cultures: Conflict, Migration and Convergence. Melbourne: The Miegunyah Press, 2009, p. 82-85.

SUMMERS, David. Real Spaces: World Art History and the Rise of Western Modernism. London; New York: Phaidon, 2003. 